\title{
The Effect of an Islamic-Based Intervention on Depression and Anxiety in Malaysia
}

\author{
Ali Ali Gobaili Saged ${ }^{1}$ D . Che Zarrina Sa'ari ${ }^{1} \cdot$ Mustaffa bin Abdullah ${ }^{1}$. \\ Waleed Mugahed Al-Rahmi ${ }^{1,2}$. Wail Muin Ismail ${ }^{3} \cdot$ Mohamed Ibrahim Adam Zain $^{4}$. \\ Nourah bint Abdullah bin Mtaib alShehri ${ }^{5}$
}

Accepted: 9 December 2021 / Published online: 3 January 2022

(c) The Author(s), under exclusive licence to Springer Science+Business Media, LLC, part of Springer Nature 2022

\begin{abstract}
Religiously integrated interventions for treating mental illnesses have proved effective. However, many studies have yet to adequately address the effects of Islamic religious-based rituals on mental health among Muslims. The present study investigated the impact of a purposefully designed Islamic religion-based intervention on reducing depression and anxiety disorders among Muslim patients using a randomised controlled trial design. A total of 62 Muslim patients (30 women and 32 men) were divided by gender into two groups, with each group assigned randomly to either treatment or control groups. The participants who received the Islamicbased intervention were compared to participants who received the control intervention. Taylor's (cite date) manifest anxiety scale and Steer and Beck's (cite the date) depression scale were used to examine the effects on depression and anxiety levels. ANCOVA results revealed that the Islamic intervention significantly reduced anxiety levels in women $(d=0.75)$ and depression levels in men $(d=0.80)$ compared to the typical care control groups.
\end{abstract}

Keywords Anxiety · Depression · Allah's forgiveness $\cdot$ Remembrance $\cdot$ Religious intervention

\section{Abbreviation}

RSAFI Remembrance and seeking Allah's forgiveness intervention

Ali Ali Gobaili Saged

saged@um.edu.my

Extended author information available on the last page of the article 


\section{Introduction}

The human life cycle comprises different stages (i.e. gestation, infancy, toddler age, childhood, puberty, youth, adulthood, middle age, and old age) associated with human development and growth (Allen, 2015). Each stage has characteristics that distinguish it from the other. According to Roberts et al. (2001), youth is a critical developmental stage with unique biological and psychological characteristics. In this stage, youth experience increased emotional disorders, including fear of the future, work pressures, life dissatisfaction, and feelings of depression and anxiety (Özdemir et al., 2016). Wars, conflicts, and social stress increase the incidence and prevalence of mental disorders, especially among youth. These conditions negatively affect young people's social relations and general performance (Mollica et al., 2004). Physical and emotional support is rooted in cultural and religious contexts, i.e. coping strategies, that address young people's psychological issues. In this context, emerging trends have shown the usefulness of religion-based interventions in treating mental illnesses (Anderson et al., 2015; Candy et al., 2012). Muslims in different parts of the world practise religionbased interventions. These interventions increase a person's faith in Almighty Allah and provide him/her with the spiritual energy to endure life's hardships and ease anxiety (Keshavarzi et al., 2020).

There are many causes of anxiety among the youth. One of these is that they become materialistic and self-centred and devote their lives to worldly affairs. This often makes them very vulnerable to mental illnesses and disorders (Hanton et al., 2002). Studies have revealed that patients show a greater tendency towards religion and spirituality (Groarke et al., 2017). Rigoli (2021) observed that anxiety about the coronavirus and prior religiosity interacted with a change in religious beliefs. Studies have also investigated the effects of selected religious interventions (i.e. reading holy books, praying, participating in spiritual discussions, listening to the Holy Quran, obtaining spiritual education) on anxiety and depression (Beiranvand et al., 2014; Zamaniyan et al., 2016). Anxiety is generally defined as a severely excessive fear of life and everyday circumstances. It creates depression among people, makes them drug addicts, and causes suicide ideation that, regrettably, occasionally ends in suicide. Hanton et al. (2002) defined anxiety as an unpleasant emotional experience, which an individual feels when he is exposed to a threatening or frightening stimulus, or when she/he stands in an acute conflictual or frustrating situation. This emotional state often accompanies physiological manifestations, such as increased heart rate, increased breathing, high blood pressure, loss of appetite, increased sweat secretion, and shivering in hands and legs, as well as the individual's perception of the surrounding issues in an anxious position. Depression, on the other hand, is defined as a mood disturbance that leads to sadness and a lack of enjoyment in daily activities. It also leads to significant weight loss, lack of sleep, thought disturbance, and inertia. Characteristics of depression include the inability to think and focus clearly, coupled with persistent feelings of worthlessness and guilt (Steffens \& Potter, 2008). Depression is among the psychological problems that individuals, to varying 
degrees, face in different environments. This mood disorder has received particular attention in medical practices and research. Researchers have also attempted to explore the nature, causes, and extent of its spread in society.

\section{Literature Review}

In $2009,3 \%$ of the world's population suffered from depression and anxiety (Newcomb \& Mustanski, 2010). Anxiety and depression are interlinked with an individual's state of mental health. For centuries, discourse and practices have been carried out to understand the link between an individual's mental health and religion. History reveals that religious groups often offer sympathetic compassionate care to mentally ill individuals. In the West and the USA, religion played an essential role in the moral treatment of mentally ill individuals (Paukert et al., 2009). Even today, depressed and anxious people seek treatment through religious rituals and prayers (Cohen, 2010). Empirical studies (Paukert et al., 2009; Rosmarin et al., 2019) have shown a significant effect of religion, religious training, spirituality, prayers, religious gatherings, and religion-based interventions on depression and anxiety (Boelens et al., 2012; Bonelli et al., 2012; Khodakarami et al., 2017; Murray et al., 2020; Papazisis et al., 2014; Paukert et al., 2009; Vasegh \& Mohammadi, 2007). Spiritual education is vital in mitigating the symptoms of anxiety and depression among patients who have multiple sclerosis. Hasan et al. (2017) argued that religion could help reduce stress, depression, and anxiety. Riba et al. (2019) said that religious therapy sessions could minimise anxiety levels compared to standard medical care. Dami et al. (2019) reported that spiritual counselling is vital to improve spiritual intelligence and reduce anxiety, stress, and depression among pregnant women. Munsoor (2021) found that people with high levels of involvement in religious activities and gatherings have a lower risk of depression and anxiety disorders. Despite the volume of research on religious "healing", limited research has investigated the impact, Islamic ritual practices have had on anxiety and depression.

In a recent study, Şirin and Göksel (2021) examined the spiritual care support given to Muslim cancer patients undergoing radiotherapy with an experimental study of these patients' spirituality, anxiety, depression, and distress levels. Adopting an experimental research design with an experimental control group revealed that the support for Islamic spiritual care had positive effects on hospitalised radiotherapy patients. In another study, Khaki and Sadeghi Habibabad (2021) investigated the impact of religious and spiritual education on the mental health of female students (2018-2019) of the Technical and Vocational University in Architecture in Tehran Province. The results indicated that religious and spiritual education positively increased the students' mental health, their social and physical performance, and decreased depression. As mentioned above, many studies have shown an increased prevalence of mental disorders, especially among the youth and adolescents, which impacts the social relations of young people and their achievements. The situation has become more severe in recent years. Therefore, a religion-based intervention has been developed to treat mental illnesses. Some studies have established the effectiveness of religion-based interventions, such as praying, spiritual discussions, listening 
to the Holy Quran, reading the Quran loudly, spiritual education, and meditation in relieving mental illnesses (Beiranvand et al., 2014; Safaei et al., 2016). Wishart et al. (2018) reported that listening to some verses of the Holy Quran affects brain activities, and thus reduces tension and enhances relaxation. This may have an impact on both the reciter and the listener. In particular, the researchers aim to investigate the impact of remembrance and seeking Allah's forgiveness intervention (RSAFI) on his or her depression and anxiety. We treated depression and anxiety as two separate dependent variables and the intervention of remembering Allah and seeking Allah's forgiveness as an independent variable.

\section{Research Questions}

This study sought answers to the following questions:

Does RSAFI affect depression?

Does RSAFI affect anxiety?

\section{Research Methods}

\section{Research Design}

This study employed a randomised controlled trial design wherein Muslim participants in Malaysia were categorised by gender into two groups. Each group was assigned into treatment and control groups randomly. The independent variables were remembrance and seeking Allah's forgiveness, whereas the dependent variables were participants' scores on the depression and anxiety scales. The two experimental groups received the intervention that cultivated seeking Allah's forgiveness and remembering Him, while the two control groups received the traditional programme, which is the energy path programme.

\section{Participants}

The target population of this research was 400 patients (177 males and 223 females) who attended the Al-Nour centre in Malaysia in 2020, seeking spiritual treatment for their depression and anxiety. They were selected using the convenience sampling method. Based on the screening test (pretest scores), 32 individuals (men) who suffered from high levels of depression were randomly assigned to two groups using random number tables: an experimental group $(N=15)$ and a control group $(N=17)$, while 30 individuals (women) who suffered from high levels of anxiety were randomly assigned into two groups using random numbers tables: an experimental group $(N=15)$ and a control group $(N=15)$. Table 1 illustrates the characteristics of the research samples according to gender and age. It was observed that $55.5 \%$ of 
Table 1 Demographic characteristics of the sample

\begin{tabular}{llll}
\hline Variable & Level & Number & Percentage \\
\hline Gender & Male & 32 & 51.6 \\
& Female & 30 & 48.4 \\
Age & Less than 30 years & 27 & 43.5 \\
& From 30 to less than 35 & 18 & 29.0 \\
& 35 years and above & 17 & 27.5 \\
Total & & 62 & \\
\hline
\end{tabular}

the participants were female with mean age $(M=34.14, \mathrm{SD}=9.14)$ and $58.3 \%$ were males with mean age $(M=35.45, \mathrm{SD}=8.90)$.

\section{Measures}

The two measures used in the current study were the Beck Depression Scale and Manifest Anxiety Scale. These two scales are explained in the following sections.

\section{Depression Scale}

The depression scale formulated by Steer and Beck (Fydrich et al., 1992; Nakamura et al., 2019) was adopted to measure the participants' depression. The scale comprises 21 items, all of which were applied. Each item consists of four phrases estimated from 0 to 3 , and the maximum overall score is 63. If the participant chooses more than one phrase, the phrase with the highest rating is used to calculate the score. The depression levels are classified according to the following rubric: from 0 to 20 (no symptoms of depression); from 21 to 31 (mild depression); from 32 to 42 (moderate depression); and from 43 to 63 (severe depression). The reliability of the scale was high (Cronbach's alpha $=87$ ).

\section{Taylor Manifest Anxiety Scale (TMAS)}

To measure the participants' anxiety level, the TMAS scale developed by Taylor (1953) was used. TMAS measures five factors: increased physiological reactivity, sleep disturbances associated with inner strain, chronic anxiety or worry, sense of personal inadequacy, and motor tension. True-false responses were used for each item. The total score for this scale ranged from 0 to 50 , where higher scores represented a higher level of anxiety. Cronbach's alpha coefficient was 77; therefore, the scale achieved adequate reliability.

\section{Overview of the Intervention}

The RSAFI was applied to the experimental groups and has several components. These components were based on moral and religious concepts and methods, including moral 
confession, repentance, insight, learning, supplication, seeking Allah's mercy, seeking forgiveness, remembrance of Allah, patience, trust in Allah, self-consciousness, piety, spiritual values, and moral principles. The techniques implemented in the intervention included the art of asking questions, clarifying, listening, interacting, summarising, persuading, feedback, empathy, training practice, reflecting feelings, discussion, and dialogue, lecturing, brainstorming, reinforcement, modelling, positive self-talk, evaluation, homework, practical applications, activation games (play through activities), emotional venting, stories, presentation, correction of thoughts, and relaxation.

The intervention comprised 30 sessions over $30 \mathrm{~h}$; two sessions were conducted per week, and each session lasted for $60 \mathrm{~min}$ (one hour). The duration of the intervention was 15 weeks. On the other hand, the two control groups received the energy path programme provided by the Al-Nour Centre. This programme aimed to enhance self-confidence and modify people's behaviour with anxiety disorders, depression, and obsessive-compulsive disorder. Similarly, the energy path programme comprised 30 sessions over $30 \mathrm{~h}$; two sessions were conducted per week, and each session lasted for $60 \mathrm{~min}$. The duration of the intervention was 15 weeks.

\section{Procedures}

The researchers received approval to conduct this study from the committee of Al-Nour Centre. To identify high scores of depression and anxiety before starting the experiment, the researchers conducted a screening test by administering the depression scale and anxiety scale to the 400 patients who attended the Al-Nour centre during 2020, seeking spiritual treatment for their depression and anxiety.

Participants who scored highly (32 men) on the depression scale and (30 women) on anxiety scales were selected to participate in the intervention. The participants were informed of their rights, provided with a copy of the consent form to sign, informed of the purpose of the study, and the confidentiality of their responses. Researchers booked one of the rooms in the Centre and asked the participants to gather in that room. They were then assigned randomly into two experimental groups and two control groups. Participants had taken part in the RSAFI intervention voluntarily.

The participants completed the intervention activities. At the end of the intervention, participants from the four groups completed the demographic data form and the depression and anxiety scale to assess improvements in the levels of depression and anxiety. Participants were informed that they could talk to the researchers if they felt distressed. Depending on the kind and severity of the distress, the researchers sought help from professional experts; however, no participant reported such distress. In total, participants completed 30 sessions with an average of two sessions per week.

\section{Data Analysis}

To answer the research questions, an analysis of covariance (ANCOVA) was used to compare the experimental group and the control group on the post-test scores after controlling the effect of the pretest. Before performing ANCOVA, the assumptions 
were checked. This comprised assessing the normality of the depression and anxiety scores, the homogeneity of variances, and the regression slopes for the covariates.

\section{Results}

This section presents the results of the randomised controlled trial study, which investigated the effectiveness of the RSAFI on reducing depression and anxiety among the participants. The results are elaborated in the following sections.

\section{Intervention Effects on Depression}

To determine the effectiveness of the RSAFI on depression among male patients, researchers performed the analysis of covariance (ANCOVA) to compare the males in the experimental group and the control group in the post-test after controlling the effect of the pretest scores. The results revealed that the mean score of the experimental group $(M=29.25, \mathrm{SD}=3.64)$ was lower than the control group's mean score $(M=44.80, S D=8.38)$. In addition, the results demonstrated a statistically significant effect of RSAFI on depression among male patients $(F(1,29)=53.452$, $p<0.01$, Cohen's $d=0.80$ ) (see Table 2). The RSAFI decreased depression among men in the experimental group with a high effect size $(d=0.80)$.

\section{Intervention Effects on Anxiety}

To determine the effectiveness of RSAFI on anxiety among female patients, ANCOVA statistical test was performed to examine the differences between the anxiety scores of females in the experimental group and the control group after controlling the effect of the pretest scores. The results revealed that the mean score of the experimental group $(M=23.60, \mathrm{SD}=4.89)$ was lower than the control group's mean score $(M=33.50, \mathrm{SD}=3.98)$. Furthermore, the results indicated that there is a statistically significant effect of the RSAFI on anxiety among female patients $(F$ $(1,29)=46.788, p<0.01$, Cohen's $d=0.75$ ) (see Table 3). Therefore, the RSAFI decreased the level of anxiety among women in the experimental group with a high effect size $(d=0.75)$ (Cohen, 1973).

Table 2 Results of ANCOVA regarding the effect of remembrance and Allah's forgiveness on depression after controlling for the effect of pretest scores (men)

\begin{tabular}{lclcrll}
\hline Source & Type III sum of squares & $d f$ & Mean square & \multicolumn{1}{c}{$F$} & Sig & Cohen's $d$ \\
\hline Pretest & 130.518 & 1 & 130.518 & 3.320 & 0.077 & 0.082 \\
Intervention & 2101.125 & 1 & 2101.125 & 53.452 & 0.000 & 0.591 \\
Error & 1454.432 & 29 & 39.309 & & & \\
Total & $58,837.000$ & 30 & & & & \\
\hline
\end{tabular}

The duration of the intervention was 15 weeks (30 sessions), and the post-intervention comparison between the groups was conducted immediately after completing all the 30 sessions 
Table 3 Results of ANCOVA regarding the effect of remembrance of Allah and Allah's forgiveness on anxiety after controlling for the effect of pretest scores (women)

\begin{tabular}{lcccccc}
\hline Source & Type III sum of squares & $d f$ & Mean square & $F$ & Sig & Cohen's $d$ \\
\hline Pretest & 49.830 & 1 & 49.830 & 2.612 & 0.115 & 0.066 \\
Intervention & 892.670 & 1 & 892.670 & 46.78 & 0.000 & 0.558 \\
Error & 705.920 & 29 & 19.079 & & & \\
Total & $33,741.000$ & 30 & & & & \\
\hline
\end{tabular}

The duration of the intervention was 15 weeks (30 sessions), and the post-intervention comparison between the groups was conducted immediately after completing all the 30 sessions

\section{Discussion}

The present study investigated the impact of Islamic religion-based interventions (RSAFI) on reducing the levels of depression and anxiety. The RSAFI significantly reduced the levels of depression and anxiety among the participants. Also, there was a substantial improvement in the patients' general health after the intervention. They were satisfied and believed that everything happening to them was destined by Allah. These results could be attributed to the different intervention practices that relied on the guidance of the Holy Quran and Sunnah. For instance, Saged et al. (2020) confirmed that the Holy Quran significantly impacts healing patients who suffer from physical, psychological, and mental disorders. In this respect, Moodley et al. (2018) concluded that having faith in Allah offers a relatively quick approach to healing patients suffering from heartache and depression. This goes hand in hand because the recitation of the Quran and remembrance of Allah help patients feel relaxed and peaceful. Muslims believe that the Quran is the word of Allah and that Allah's words exert a significant impact on the healing of mental health patients, as, ultimately, Almighty Allah is the one who cures illnesses.

\section{Trust in Allah}

Allah tests individuals with this psychological imbalance and can free them from psychological problems, and He can even compensate them with something much better. In this situation, Moodley et al. (2018) stated that the Quran describes adversities, such as having a health problem, as a test from Allah, and indicates the individual is not responsible for the mental illness. Allah says, "If Allah touches thee with hurt, there is none can remove it but He: if He does design some benefit for thee, there is none can keep back His favour: He causeth it to reach whomsoever of His servants He pleased. In addition, He is the Oft-Forgiving, Most Merciful" (Quranic Arabic Corpus, 2017). The findings of this study demonstrated that remembering Allah and seeking Allah's forgiveness help cure a person with psychiatric problems. When humans feel that they may be granted forgiveness, this provides them with psychological relief. In this situation, forgiveness offers a positive emotional state and hopefulness. 


\section{Repentance}

A believer who feels the constant presence of Allah tends to commit fewer sins. Seeking forgiveness is essential so that Allah may forgive them. That is, a person should stop committing sins and stick to the path of Allah. Prophet Mohammed (PBUH) said, "all the sons of Adam are sinners, but the best of sinners are those who repent often" (Tirmidhi, 16/1520). Allah keeps the door of forgiveness open to all those seeking his forgiveness. Prophet Mohammed (PBUH) narrates what Allah says: "My servants, I have made oppression unlawful for Me and unlawful for you, so do not commit oppression against one another. All sons of Adam commit sins day and night, and once they ask My forgiveness, I never hesitate to forgive them" (An-Nawawi, 24). These Hadiths indicate that Allah grants His servants a chance to seek forgiveness directly. This draws people closer to Allah and cultivates purity and calmness. Psychological complexes are never an illusion, as many cause headaches, heart disorders, hypertension, and other diseases. Since the psychological complexes are treated when a patient shares their thoughts with a psychiatrist, how does it differ from confessing to Allah, and what is the difference between Allah's forgiveness and that of the conscience?

\section{Confessing Sins and Seeking Forgiveness}

The concepts of confessing sins and seeking forgiveness exist in the Quran as being more useful and comprehensive than one's confession before a psychiatrist. This is because the Quranic solution to psychiatric problems helps one rid themselves of adversity and disorders. For example, when Prophet Younis (PBUH) was in the whale's belly, he confessed his sin to Allah and sought Allah's forgiveness. As a result, Allah forgave him and saved him from his dilemma. Allah also guided Adam and Eve to seek forgiveness after they disobeyed Him. Allah says, They said, "Our Lord, we have wronged ourselves, and if You do not forgive us and have mercy upon us, we will surely be among the losers". Seeking Allah's forgiveness requires sincere repentance, i.e. Allah says, "Seek forgiveness of your Lord and repent to Him, [and] He will let you enjoy a good provision for a specified term and give every doer of favour his favour. But if you turn away, then indeed, I fear for you the punishment of a Great Day" (Qur'an 10: 107).

Thus, seeking forgiveness and repentance brings relief, happiness, blessing, calmness, and straightforwardness. This will also bring one more provision. Therefore, Muslims should seek Allah's forgiveness by refraining from sins and showing sincere repentance. Allah says, "And hasten to forgiveness from your Lord and a garden as wide as the heavens and earth, prepared for the righteous" (Qur'an 3: 133). Overall, our results are consistent with the findings of several studies (Kang \& Romo, 2011). Herein was a significant impact of religious interventions on decreasing the levels of depression and anxiety, and the difference between the religious beliefs and depression and hopelessness levels of the cancer patients was statistically significant. 


\section{The Impact of the Intervention on Depression}

As indicated earlier, RSAFI significantly reduced the levels of depression and anxiety among the participants. Furthermore, the levels of depression and hopelessness among cancer patients were moderate, and their religious beliefs were high. Hossain and Rizvi (2016) reported that people suffering from depression typically have low self-esteem and suicidal tendencies. This could be cured through religious practices and activities that help cure mental disorders and illnesses. In another study, Kang and Romo (2011) indicated that those consistently engaged with church activities are usually spiritually stronger than those who are not engaged with church activities, which leads to significantly lower levels of depression among girls. Vasegh (2011) revealed that many studies reported that religious behaviours, cognitions, and techniques added to psychotherapy are effective in patients recovering from anxiety and depression. Padela and Curlin (2013) reported that religious practices and rituals affect how individuals seek help to eliminate mental disorders.

\section{The Impact of the Intervention on Anxiety}

The results of the current study provided evidence about the effectiveness of RSAFI on reducing the levels of anxiety among the participants. This could be attributed to the fact that a strong religious background is required for psychotherapy to be successful. Religious discussions with patients had a significant impact on their thinking, allowing them to readjust to the ideal value system because these patients are close to Allah and always ask for His forgiveness once they were convinced that Allah had forgiven them (Razali et al., 1998). It was scientifically proven that belief in Allah accelerated the healing of patients and rids them of anxiety and other psychological disorders. Doctors also recommended considering the patients' religiosity, as faith and remembrance of Allah have a strong influence on patients' response to physical or spiritual treatment (Saged, 2012).

Undoubtedly, the Holy Qur' an has a great effect in achieving comfort and heartfelt tranquillity (Saged, 2012). Allen and colleagues interviewed 73 adult male inmates in the USA and discovered that God and religious experiences had a favourable impact on the anxiety of older offenders (Stewart et al., 2019). In another study, those who are more religious reported low levels of anxiety. The finding of this study is also supported by the findings of DeRossett et al. (2021) who indicated that positive religious coping is associated with low levels of anxiety. Ahmad (1990) conducted a study on Egyptian students about moral anxiety and its relationship to religious values and concepts. He found that studying religious science reduces the level of anxiety among students.

\section{Implications of the Study}

The importance of the present study lies in the researchers' attempt to find a psychological treatment based on the guidance of the Quran and Sunnah to treat depression 
and anxiety. It deals with humans in an integrated and comprehensive way at a spiritual level. Additionally, it helps counselling and psychotherapy specialists ease depression and anxiety. The study addresses alleviating symptoms of depression and anxiety in the age between 29 and 40 years, which is a period of productivity and creativity.

\section{Limitations}

The sample of this study was limited to the patients with anxiety and depression disorders at the Al-Nour Centre in Kuala Lumpur, so the results cannot be generalised to other samples. Furthermore, the treatment of anxiety was restricted to females, whereas the treatment of depression was restricted to males. Additionally, the selection of females and males as samples for the study was based on their pre-measurement of anxiety and depression, which serve as self-report measures.

\section{Conclusion}

In the present study, religious intervention played a vital role in lowering the patients' level of anxiety among women and depression among men. In general, religious practices prevent individuals from becoming subject to mental disorders, i.e. anxiety and depression.

\section{Declarations}

Conflict of interest The author has no conflicts of interest to declare that are relevant to the content of this article.

Ethical Approval The researchers received approval to conduct this study from the committee of Al-Nour Centre. The participants were informed of their rights, provided with a copy of the consent form to sign, and informed of the purpose of the study.

Human and animal rights According to ethical rule, this research is not applied in human and animal studies at all.

\section{References}

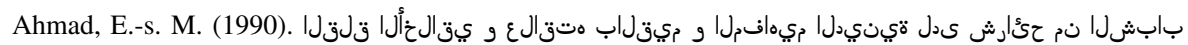

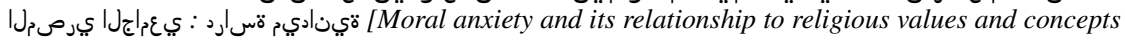
among of Egyptian university students: a field study] Ain-Shams University]. Egypt

Allen, B. P. (2015). Personality theories: Development, growth, and diversity. Psychology Press.

Anderson, N., Heywood-Everett, S., Siddiqi, N., Wright, J., Meredith, J., \& McMillan, D. (2015). Faithadapted psychological therapies for depression and anxiety: Systematic review and meta-analysis. Journal of Affective Disorders, 176, 183-196. https://doi.org/10.1016/j.jad.2015.01.019

Beiranvand, S., Valizadeh, F., Hosseinabadi, R., \& Pournia, Y. (2014). The effects of skin-to-skin contact on temperature and breastfeeding successfulness in full-term newborns after cesarean delivery. International Journal of Pediatrics. https://doi.org/10.1155/2014/846486 
Boelens, P. A., Reeves, R. R., Replogle, W. H., \& Koenig, H. G. (2012). The effect of prayer on depression and anxiety: Maintenance of positive influence one year after prayer intervention. The International Journal of Psychiatry in Medicine, 43(1), 85-98. https://doi.org/10.2190/PM. 43.1.f

Bonelli, R., Dew, R. E., Koenig, H. G., Rosmarin, D. H., \& Vasegh, S. (2012). Religious and spiritual factors in depression: Review and integration of the research. Depression Research and Treatment. https://doi.org/10.1155/2012/962860

Candy, B., Jones, L., Varagunam, M., Speck, P., Tookman, A., \& King, M. (2012). Spiritual and religious interventions for well-being of adults in the terminal phase of disease. Cochrane Database of Systematic Reviews. https://doi.org/10.1002/14651858

Cohen, J. (1973). Eta-squared and partial eta-squared in fixed factor ANOVA designs. Educational and Psychological Measurement, 33, 107-112. https://doi.org/10.1111/j.1468-2958.2002.tb00828.x

Cohen, W. M. (2010). Fifty years of empirical studies of innovative activity and performance. Handbook of the Economics of Innovation, 33(1), 107-112. https://doi.org/10.1177/001316447303300 111

Dami, Z. A., Setiawan, I., Sudarmanto, G., \& Lu, Y. (2019). Effectiveness of group counseling on depression, anxiety, stress and components of spiritual intelligence in student. International Journal of Scientific \&amp; Technology Research, 8(9), 236-243.

DeRossett, T., LaVoie, D. J., \& Brooks, D. (2021). Religious coping amidst a pandemic: Impact on COVID-19-related anxiety. Journal of Religion and Health, 60(5), 3161-3176. https://doi.org/ 10.1007/s10943-021-01385-5

Fydrich, T., Dowdall, D., \& Chambless, D. L. (1992). Reliability and validity of the beck anxiety inventory. Journal of Anxiety Disorders, 6(1), 55-61. https://doi.org/10.1016/0887-6185(92) 90026-4

Groarke, A., Curtis, R., Groarke, J. M., Hogan, M. J., Gibbons, A., \& Kerin, M. (2017). Post-traumatic growth in breast cancer: How and when do distress and stress contribute? Psycho-Oncology, 26(7), 967-974. https://doi.org/10.1002/pon.4243

Hanton, S., Mellalieu, S. D., \& Young, S. G. (2002). A qualitative investigation of the temporal patterning of the precompetitive anxiety response. Journal of Sports Sciences, 20(11), 911-928. https://doi.org/10.1080/026404102320761804

Hasan, E. M., Tabei, S. Z., Mahmoodabad, S. S. M., Fallahzadeh, H., Nami, M., Doroudchi, M., \& Forouhari, S. (2017). Studying the relationship between university students' anxiety and depression with religious orientation, quality of sleep and emotional cognitive adjustment. NeuroQuantology. https://doi.org/10.14704/nq.2017.15.4.1155

Hossain, M. Z., \& Rizvi, M. A. K. (2016). Relationship between religious belief and happiness in Oman: A statistical analysis. Mental Health, Religion and Culture, 19(7), 781-790. https://doi. org/10.1080/13674676.2017.1280009

Kang, P. P., \& Romo, L. F. (2011). The role of religious involvement on depression, risky behavior, and academic performance among Korean American adolescents. Journal of Adolescence, 34(4), 767-778. https://doi.org/10.1016/j.adolescence.2010.08.003

Keshavarzi, H., Khan, F., Ali, B., \& Awaad, R. (2020). Applying Islamic principles to clinical mental health care: Introducing traditional Islamically integrated psychotherapy. Routledge.

Khaki, A., \& Sadeghi Habibabad, A. (2021). Investigating the effect of religious and Islamic teachings on the calmness and mental health in educational spaces. Journal of Religion and Health, 60(4), 2632-2645. https://doi.org/10.1007/s10943-020-01022-7

Khodakarami, B., Golalizadeh Bibalan, F., Soltani, F., Soltanian, A., \& Mohagheghi, H. (2017). Impact of a counseling program on depression, anxiety stress and spiritual intelligence in pregnant women. Journal of Midwifery and Reproductive Health, 5(2), 858-866. https://doi.org/10. 22038/JMRH.2016.7755

Mollica, R., Guerra, R., \& Bhasin, R. (2004). Trauma and the role of mental health in the post-conflict recovery. Book of best practices. Harvard Programme in Refugee Trauma.

Moodley, P., Joosub, N., \& Khotu, R. S. (2018). Conceptions of depression of muslim clergy in a faith-based organization in South Africa. Journal of Muslim Mental Health. https://doi.org/10. 3998/jmmh.10381607.0012.104

Munsoor, M. S. (2021). Wellbeing and the worshipper: Insights into an islamic spiritual order. Springer.

Murray, C. J., Aravkin, A. Y., Zheng, P., Abbafati, C., Abbas, K. M., Abbasi-Kangevari, M., AbdAllah, F., Abdelalim, A., Abdollahi, M., \& Abdollahpour, I. (2020). Global burden of 87 risk 
factors in 204 countries and territories, 1990-2019: A systematic analysis for the Global Burden of Disease Study 2019. The Lancet, 396(10258), 1223-1249. https://doi.org/10.1016/S01406736(20)30752-2

Nakamura, A., van der Waerden, J., Melchior, M., Bolze, C., El-Khoury, F., \& Pryor, L. (2019). Physical activity during pregnancy and postpartum depression: Systematic review and meta-analysis. Journal of Affective Disorders, 1(246), 29-41. https://doi.org/10.1016/j.jad.2018.12.009

Newcomb, M. E., \& Mustanski, B. (2010). Internalized homophobia and internalizing mental health problems: A meta-analytic review. Clinical Psychology Review, 30(8), 1019-1029. https://doi. org/10.1016/j.cpr.2010.07.003

Özdemir, A., Utkualp, N., \& Palloş, A. (2016). Physical and psychosocial effects of the changes in adolescence period. International Journal of Caring Sciences, 9(2), 717-723.

Padela, A. I., \& Curlin, F. A. (2013). Religion and disparities: Considering the influences of Islam on the health of American Muslims. Journal of Religion and Health, 52(4), 1333-1345. https://doi. org/10.1007/s10943-012-9620-y

Papazisis, G., Nicolaou, P., Tsiga, E., Christoforou, T., \& Sapountzi-Krepia, D. (2014). Religious and spiritual beliefs, self-esteem, anxiety, and depression among nursing students. Nursing and Health Sciences, 16(2), 232-238. https://doi.org/10.1111/nhs.12093

Paukert, A. L., Phillips, L., Cully, J. A., Loboprabhu, S. M., Lomax, J. W., \& Stanley, M. A. (2009). Integration of religion into cognitive-behavioral therapy for geriatric anxiety and depression®. Journal of Psychiatric Practice, 15(2), 103-112. https://doi.org/10.1097/01.pra.0000348363. $88676.4 \mathrm{~d}$

Razali, S. M., Hasanah, C. I., Aminah, K., \& Subramaniam, M. (1998). Religious-sociocultural psychotherapy in patients with anxiety and depression. Australian and New Zealand Journal of Psychiatry, 32(6), 867-872. https://doi.org/10.3109/00048679809073877

Riba, M. B., Donovan, K. A., Andersen, B., Braun, I., Breitbart, W. S., Brewer, B. W., Buchmann, L. O., Clark, M. M., Collins, M., \& Corbett, C. (2019). Distress management, version 3. 2019, NCCN clinical practice guidelines in oncology. Journal of the National Comprehensive Cancer Network, 17(10), 1229-1249. https://doi.org/10.6004/jnccn.2019.0048

Rigoli, F. (2021). The Link Between COVID-19, Anxiety, and Religious Beliefs in the United States and the United Kingdom. Journal of Religion and Health. https://doi.org/10.1007/ s10943-021-01296-5

Roberts, B. W., Caspi, A., \& Moffitt, T. E. (2001). The kids are alright: Growth and stability in personality development from adolescence to adulthood. Journal of Personality and Social Psychology, 81(4), 670. https://doi.org/10.1037/0022-3514.81.4.670

Rosmarin, D. H., Bocanegra, E. S., Hoffnung, G., \& Appel, M. (2019). Effectiveness of cognitive behavioral therapy for anxiety and depression among Orthodox Jews. Cognitive and Behavioral Practice, 26(4), 676-687. https://doi.org/10.1016/j.cbpra.2019.07.005

Safaei, A., Oskouie, A. A., Mohebbi, S. R., Rezaei-Tavirani, M., Mahboubi, M., Peyvandi, M., Okhovatian, F., \& Zamanian-Azodi, M. (2016). Metabolomic analysis of human cirrhosis, hepatocellular carcinoma, non-alcoholic fatty liver disease and non-alcoholic steatohepatitis diseases. Gastroenterology and Hepatology from Bed to Bench, 9(3), 158.

Saged, A. A. G. (2012). Miracle of quranic effects in the treatment of psychological diseases: An analytical field study. University of Malaya.

Saged, A. A. G., Yusoff, M. Y. Z. M., Latif, F. A., Hilmi, S. M., Al-Rahmi, W. M., Al-Samman, A., Alias, N., \& Zeki, A. M. (2020). Impact of Quran in treatment of the psychological disorder and spiritual illness. Journal of Religion and Health, 59(4), 1824-1837. https://doi.org/10.1007/ s10943-018-0572-8

Şirin, T., \& Göksel, F. (2021). Investigation of the spiritual care effects on anxiety, depression, psychological distress and spiritual levels of Turkish muslim radiotherapy patients. Journal of Religion and Health, 60(4), 2484-2502. https://doi.org/10.1007/s10943-020-01117-1

Steffens, D. C., \& Potter, G. (2008). Geriatric depression and cognitive impairment. Psychological Medicine, 38(2), 163-175. https://doi.org/10.1017/S003329170700102X

Stewart, W., Wetselaar, M., Nelson, L., \& Stewart, J. (2019). Review of the effect of religion on anxiety. International Journal of Depression and Anxiety. https://doi.org/10.23937/2643-4059/17100 16

Taylor, J. A. (1953). A personality scale of manifest anxiety. The Journal of Abnormal and Social Psychology, 48(2), 285. https://doi.org/10.1037/h0056264 
Vasegh, S. (2011). Cognitive therapy of religious depressed patients: Common concepts between Christianity and Islam. Journal of Cognitive Psychotherapy, 25(3), 177. https://doi.org/10.1891/ 0889-8391.25.3.177

Vasegh, S., \& Mohammadi, M.-R. (2007). Religiosity, anxiety, and depression among a sample of Iranian medical students. The International Journal of Psychiatry in Medicine, 37(2), 213-227. https://doi.org/10.2190/J3V5-L316-0U13-7000

Wishart, D. S., Feunang, Y. D., Guo, A. C., Lo, E. J., Marcu, A., Grant, J. R., Sajed, T., Johnson, D., Li, C., \& Sayeeda, Z. (2018). DrugBank 5.0: a major update to the DrugBank database for 2018. Nucleic Acids Research, 46(D1), D1074-D1082. https://doi.org/10.1093/nar/gkx1037

Zamaniyan, S., Bolhari, J., Naziri, G., Akrami, M., \& Hosseini, S. (2016). Effectiveness of spiritual group therapy on quality of life and spiritual well-being among patients with breast cancer. Iranian Journal of Medical Sciences, 41(2), 140-144.

Publisher's Note Springer Nature remains neutral with regard to jurisdictional claims in published maps and institutional affiliations.

\title{
Authors and Affiliations
}

\section{Ali Ali Gobaili Saged ${ }^{1}$ (1) . Che Zarrina Sa'ari ${ }^{1} \cdot$ Mustaffa bin Abdullah ${ }^{1}$. Waleed Mugahed Al-Rahmi ${ }^{1,2}$. Wail Muin Ismail ${ }^{3}$. Mohamed Ibrahim Adam Zain ${ }^{4}$. Nourah bint Abdullah bin Mtaib alShehri ${ }^{5}$}

\author{
Che Zarrina Sa'ari \\ zarrina@um.edu.my \\ Mustaffa bin Abdullah \\ mustaffa@um.edu.my \\ Waleed Mugahed Al-Rahmi \\ waleed.alrahmi@yahoo.com \\ Wail Muin Ismail \\ wailismail@um.edu.my \\ Mohamed Ibrahim Adam Zain \\ abuasmaa4@gmail.com
}

Nourah bint Abdullah bin Mtaib alShehri naalshehri@pnu.edu.sa

1 Academy of Islamic Studies, University of Malaya, 50603 Kuala Lumpur, Malaysia

2 Faculty of Education, Universiti Teknologi Malaysia, Johor, Malaysia

3 Faculty of Education, University of Malaya, 50603 Kuala Lumpur, Malaysia

4 Islamic Banking and Finance, International Islamic University Malaysia, Selangor, Malaysia

5 Department of Hadith and Associated Sciences, Nourah Bint Abdulrahman University, Riyadh, Saudi Arabia 